\title{
Thermomechanical behavior of different Ni-base superalloys during cyclic loading at elevated temperatures
}

\author{
Daniel Huber ${ }^{1, a}$, Matthias Hacksteiner ${ }^{2,3}$, Cecilia Poletti $^{2}$, Fernando Warchomicka $^{2}$, and Martin Stockinger ${ }^{1}$ \\ ${ }^{1}$ Böhler Schmiedetechnik GmbH \& Co KG, Kapfenberg, Austria \\ ${ }^{2}$ Institute of Materials Science and Welding, Graz University of Technology, Austria \\ ${ }^{3}$ Institute for Production Engineering and Laser Technology, Vienna University of Technology, Austria
}

\begin{abstract}
The material behavior of three Ni-base superalloys (Inconel ${ }^{\circledR} 718$, Allvac ${ }^{\circledR} 718$ Plus ${ }^{\mathrm{TM}}$ and Haynes ${ }^{\circledR} 282^{\circledR}$ ) during in-phase cyclic mechanical and thermal loading was investigated. Stress controlled thermo-mechanical tests were carried out at temperatures above $700^{\circ} \mathrm{C}$ and different levels of maximum compressive stress using a Gleeble ${ }^{\circledR} 3800$ testing system. Microstructure investigations via light optical microscopy (LOM) and field emission gun scanning electron microscopy (FEG-SEM) as well as numerical precipitation kinetics simulations were performed to interpret the obtained results. For all alloys, the predominant deformation mechanism during deformation up to low plastic strains was identified as dislocation creep. The main softening mechanism causing progressive increase of plastic strain after preceding linear behavior is suggested to be recrystallization facilitated by coarsening of grain boundary precipitates. Furthermore, coarsening and partial transformation of strengthening phases was observed. At all stress levels, Haynes ${ }^{\circledR} 282^{\circledR}$ showed best performance which is attributable to its stable microstructure containing a high phase fraction of small, intermetallic precipitates inside grains and different carbides evenly distributed along grain boundaries.
\end{abstract}

\section{Introduction}

A strong demand for higher efficiency, reduced fuel consumption, $\mathrm{CO}_{2}$ and $\mathrm{NO}_{x}$ emissions as well as weight reduction in aircraft engines lead to a substitution of presently used materials by novel light-weight, high temperature materials like $\gamma$-TiAl alloys. Hot-working of TiAl alloys, however, is a complex and challenging task due to a small processing window. Isothermal forging, as state of the art process, uses Mo-based die material to withstand high processing temperatures.

Böhler Schmiedetechnik $\mathrm{GmbH} \& \mathrm{Co} \mathrm{KG}$ has developed a hot-die forging process with die temperatures above $700{ }^{\circ} \mathrm{C}$. These temperatures necessitate the use of high temperature resistance materials as die material [1]. In order to produce sound forgings in an economic process, following requirements arise for the die material: temperature resistance and microstructural stability at temperatures above $700^{\circ} \mathrm{C}$, low thermal expansion, good machinability, good weldability and oxidation resistance at operation temperature. Literature study and company experience favored three different alloys: (the Ni-base superalloy working horse) Inconel ${ }^{\circledR} 718$, ATI's Allvac ${ }^{\circledR}$ 718 Plus $^{\mathrm{TM}}$ and Haynes ${ }^{\circledR} 282^{\circledR}$.

Aim of the present work was to compare the applicability of the three Ni-base superalloys as promising die material for TiAl turbine blade hot-die forging.

\footnotetext{
${ }^{a}$ Corresponding author: daniel .huber@bohler-forging.com
}

\section{Experimental}

\subsection{Materials and heat treatment}

\subsection{Inconel ${ }^{\circledR} 718$}

Double melt (VIM + VAR) Inconel ${ }^{\circledR} 718$ material with a billet size of round 5" $(127 \mathrm{~mm})$ was used. The chemical composition in wt.\% from heat lot analysis is shown in Table 1. The billet was solution annealed at $1010^{\circ} \mathrm{C}$ for 1 hour with subsequent air cooling. The temperature was chosen to solubilize a high amount of $\mathrm{Nb}$ and simultaneously retaining a certain amount of grain boundary stabilizing $\delta$ phase. This $\mathrm{Nb}$ in the matrix favors the precipitation of a high amount of $\gamma^{\prime \prime}$ phase during aging. Single step aging was performed at $788^{\circ} \mathrm{C}$ for 6 hours, followed by air cooling [2]. Final grain size varied between $60 \mu \mathrm{m}$ and $140 \mu \mathrm{m}$ and an average $\gamma^{\prime \prime}$ volume phase fraction of $14 \%$ was measured from image analysis. The disk-shaped precipitates showed a characteristic size of $70 \pm 15 \mathrm{~nm}$ and an aspect ratio of $0.35 \pm 0.1$. Plate-like $\delta$ phase was found along grain boundaries, as shown in Fig. 1.

To verify results from microstructural analysis, numerical precipitation kinetics simulations were performed by use of the software package (c)MatCalc. Results for Inconel ${ }^{\circledR} 718$ after full heat treatment are shown in Fig. 2.

Calculated volume fraction of $\gamma^{\prime \prime}$ was $12.2 \%$ with a mean diameter of $85 \mathrm{~nm}$ and a volume fraction of $1.3 \%$ $\delta$ with a particle diameter of $392 \mathrm{~nm}$. Additionally, $3.8 \%$ 
Table 1. Chemical composition of the three alloys.

\begin{tabular}{|c|c|c|c|c|c|}
\hline & Co & $\mathrm{Cr}$ & $\mathbf{F e}$ & Mo & $\mathbf{W}$ \\
\hline Inconel ${ }^{\circledR} 718$ & 0.15 & 19.32 & 17.50 & 2.99 & - \\
\hline Allvac $^{\circledR} 718$ Plus $^{\mathrm{TM}}$ & 9.16 & 17.92 & 9.34 & 2.69 & 1.0 \\
\hline \multirow[t]{2}{*}{ Haynes $^{\circledR} 282^{\circledR}$} & 10.38 & 19.45 & 0.79 & 8.52 & - \\
\hline & Al & Ti & $\mathbf{N b}$ & $\mathbf{C}$ & $\mathrm{Ni}$ \\
\hline Inconel ${ }^{\circledR} 718$ & 0.49 & 0.95 & 5.20 & 0.02 & bal. \\
\hline Allvac $^{\circledR}$ 718Plus ${ }^{\mathrm{TM}}$ & 1.51 & 0.75 & 5.50 & 0.02 & bal. \\
\hline Haynes $^{\circledR} 282^{\circledR}$ & 1.57 & 2.13 & - & 0.06 & bal. \\
\hline
\end{tabular}

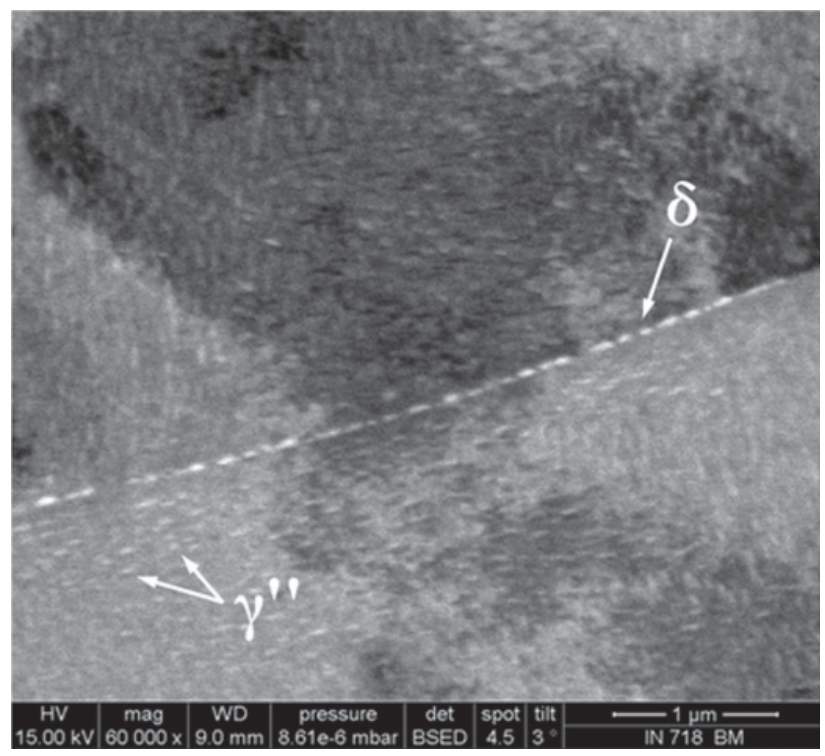

Figure 1. FEG-SEM image of undeformed Inconel ${ }^{\circledR} 718$.

of $\gamma^{\prime}$ with a diameter of $36 \mathrm{~nm}$ was calculated although it could not be detected in FEG-SEM.

\subsubsection{Allvac $^{\circledR} 718$ Plus $^{\mathrm{TM}}$}

Triple melt (VIM + ESR + VAR) Allvac ${ }^{\circledR} 718$ Plus $^{\mathrm{TM}}$ with a billet size of round $8 "(203.2 \mathrm{~mm})$ was used. The chemical composition in wt.\% from heat lot analysis is summarized in Table 1. The bar was solution annealed at $968^{\circ} \mathrm{C}$ for one hour and air cooled, followed by two-step aging $\left(788^{\circ} \mathrm{C}\right.$ for 8 hours, furnace cooling with $56^{\circ} \mathrm{C} / \mathrm{h}$ and $704^{\circ} \mathrm{C}$ for 8 hours), as suggested by W.D. Cao, et al. [3], to obtain about $4 \% \delta$ phase for grain boundary stabilization. A final grain size between $45 \mu \mathrm{m}$ and $55 \mu \mathrm{m}$ and a $\gamma^{\prime}$ volume phase fraction of $16 \%$ was achieved. The spherical $\gamma^{\prime}$ precipitates showed a diameter of $80 \pm 15 \mathrm{~nm}$ (see Fig. 3). These results are in good correlation with (C) MatCalc simulations, which predicted $16.4 \%$ volume fraction of $\gamma^{\prime}$ with a mean diameter of $76 \mathrm{~nm}$ and $3.3 \%$ volume fraction of $\delta$ with a diameter of $422 \mathrm{~nm}$.

\subsubsection{Haynes ${ }^{\circledR} 282$}

Double melt (VIM + VAR) Haynes ${ }^{\circledR} 282^{\circledR}$ with a billet size of round corned square 12 " (304.8 mm) was used. The chemical composition in wt.\% from heat lot analysis is

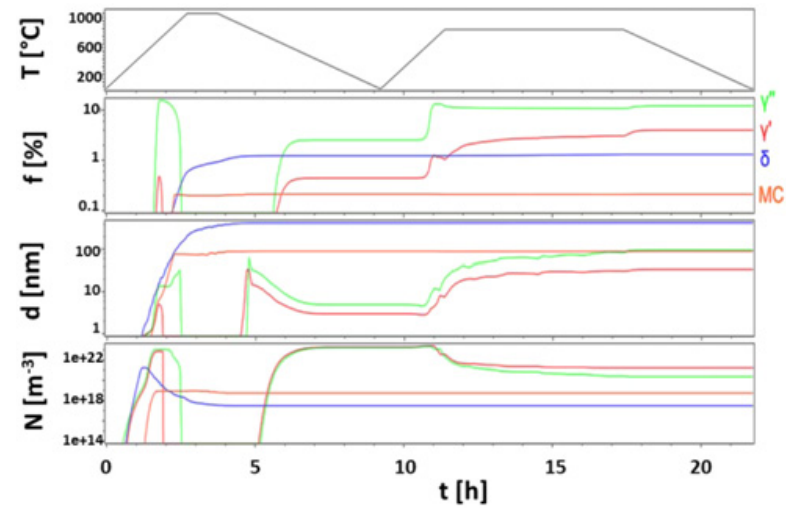

Figure 2. Results from (C) MatCalc precipitation kinetics simulations for Inconel ${ }^{\circledR} 718$.

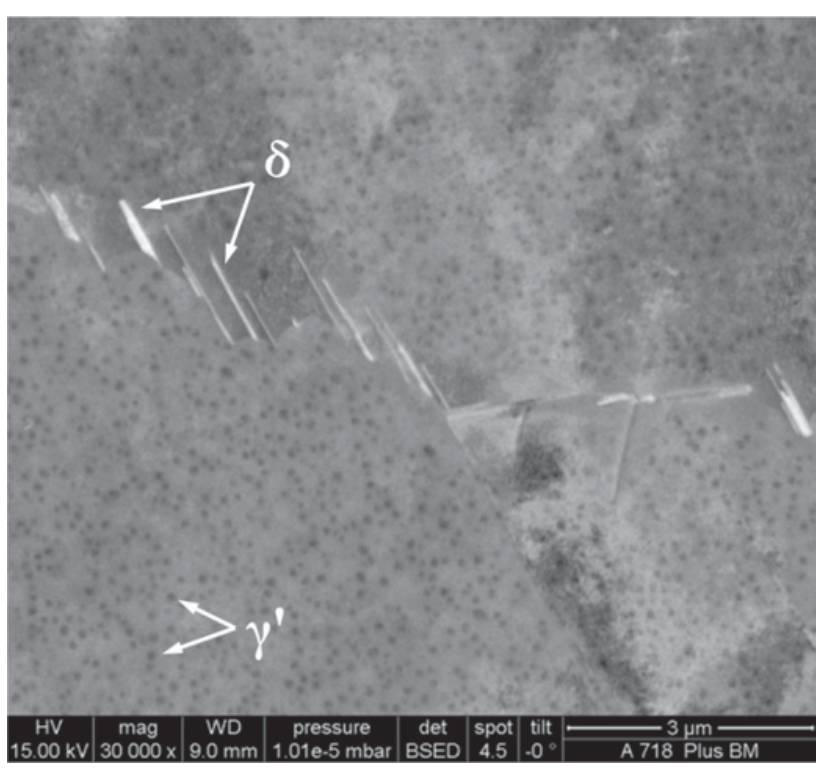

Figure 3. FEG-SEM image of undeformed Allvac ${ }^{\circledR} 718$ Plus $^{\mathrm{TM}}$.

shown in Table 1. The bar was heat treated at $1010^{\circ} \mathrm{C}$ for 2 hours with subsequent air cooling followed by 8 hours annealing at $788^{\circ} \mathrm{C}$, as proposed by L. Pike [4]. A final grain size between $150 \mu \mathrm{m}$ and $180 \mu \mathrm{m}$ and a $\gamma^{\prime}$ volume phase fraction of $18 \%$ were measured. The spherical precipitates had a mean diameter of $35 \pm 5 \mathrm{~nm}$. Figure $4 \mathrm{a}$ shows the distribution of $\gamma^{\prime}$ particles inside a grain and Fig. 4b is a detailed illustration of grain boundary carbides. (C)MatCalc calculations predicted a volume fraction of $18.4 \% \gamma^{\prime}$ with a mean diameter of $28 \mathrm{~nm}$. Carbides were identified as $\mathrm{M}_{6} \mathrm{C}$ and $\mathrm{M}_{23} \mathrm{C}_{6}$ with $\mathrm{M}$ being $\mathrm{Cr}$, Ni, Mo [5].

\subsection{Sample preparation}

Cylindrical Gleeble ${ }^{\circledR}$ tensile samples were machined out of the heat treated billets according to Fig. 5. Except for Inconel ${ }^{\circledR} 718$ specimens, the main axis of the machined specimen was perpendicular to the longitudinal axis of bar material. For Inconel ${ }^{\circledR} 718$ samples, the specimen axis was parallel to the longitudinal axis. Cylindrical samples were cut out of the bars via wire-cut electrical discharge 

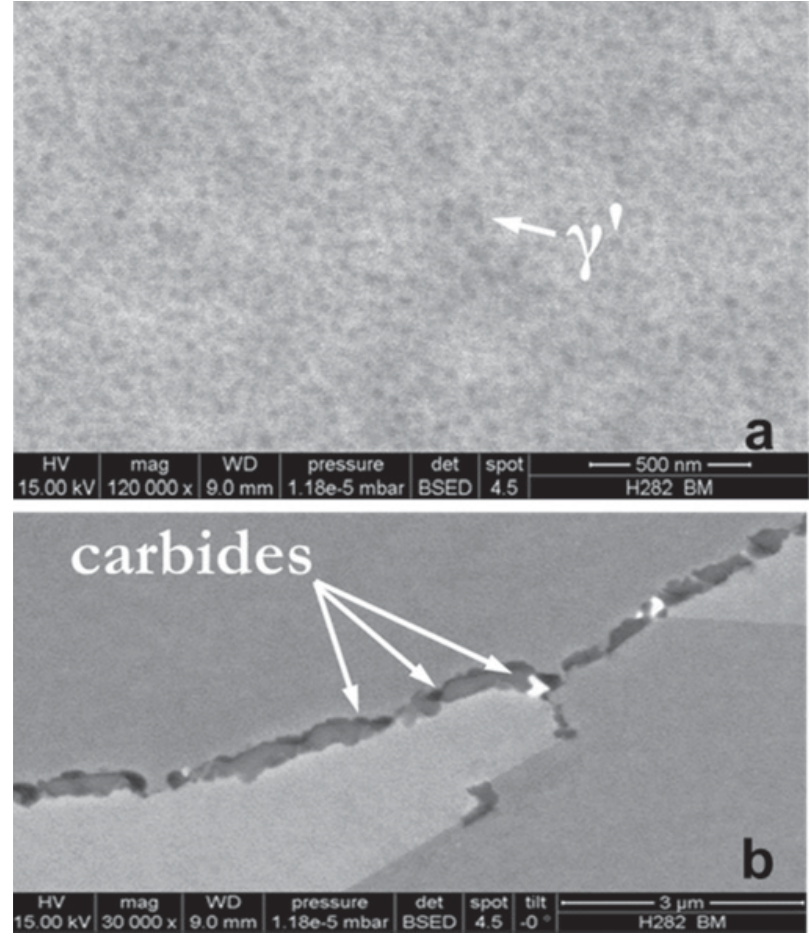

Figure 4. FEG-SEM image of undeformed Haynes ${ }^{\circledR} 282^{\circledR}$.

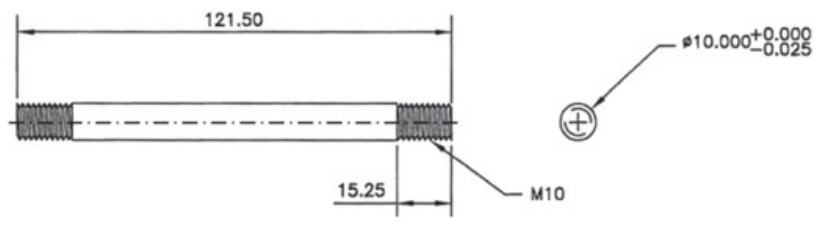

Figure 5. Tensile sample for physical forging simulation.

machining. Finally, threads were machined on the samples and the small burr from electrical discharge machining was removed by use of grinding paper.

For temperature control, type $\mathrm{K}$ thermocouples (NiCr-Ni) were used because of their low cost and good weldability to Ni-base alloy specimens. The two thermocouple wires with a diameter of $0.2 \mathrm{~mm}$ were spot-welded on the specimens' center, perpendicular to their main axis $1 \mathrm{~mm}$ apart from each other using a DSI Thermocouple Welder 35200.

\subsection{Gleeble $^{\circledR} 3800$ testing setup}

All thermo-mechanical tests were performed on a DSI Gleeble ${ }^{\circledR} 3800$ testing system. The device contains a resistance heating system for heating rates of up to $10000^{\circ} \mathrm{C} / \mathrm{s}$. Samples can be quenched with air, inert gas or water. The hydraulic servo system is capable of exerting static forces of up to $98 \mathrm{kN}$ in tension and $196 \mathrm{kN}$ in compression with a maximum speed of $2000 \mathrm{~mm} / \mathrm{s}$.

The physical forging simulations were carried out with parameters related to mechanical and thermal loads during real forging processes. For that, real temperature and stress profiles were obtained from finite element forging simulations done in the software package Deform $3 \mathrm{D}^{\mathrm{TM}}$.

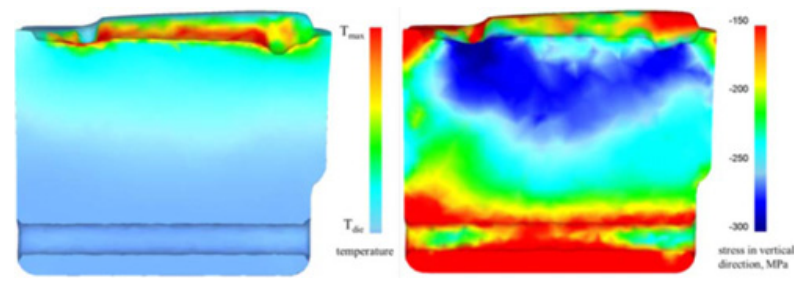

Figure 6. Maximum temperature (left) and stress (right) distribution in the lower die during forging.

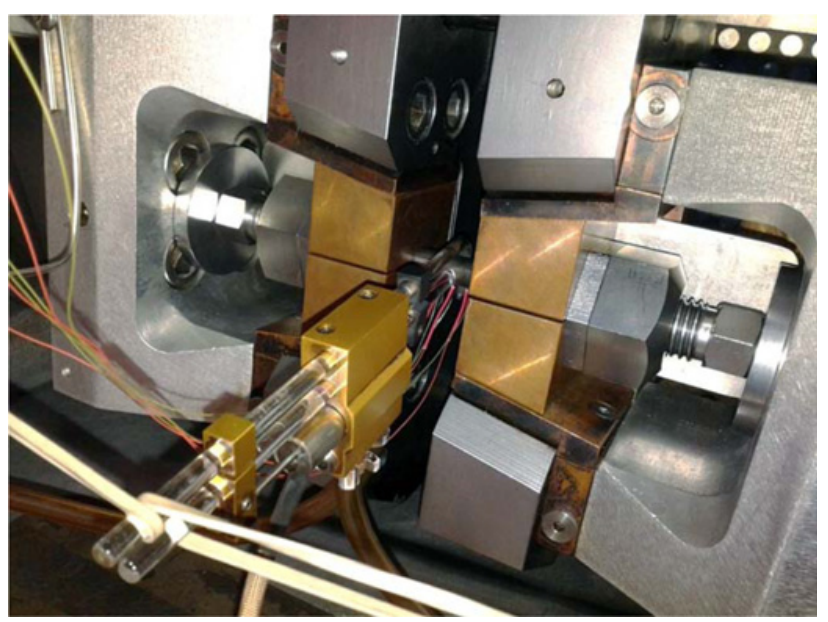

Figure 7. Setup of experiments at the Gleeble ${ }^{\circledR} 3800$.

A cross section through the highest loaded part of the die is shown in Fig. 6.

Based on results from numerical simulation, three maximum mechanical compression stresses were defined as $-450 \mathrm{MPa},-350 \mathrm{MPa}$ and $-300 \mathrm{MPa}$.

The tensile specimens were fixed in axial direction for physical forging simulation. Therefore, a two-stage clamping process was utilized. First, the specimen was clamped in tensile direction pneumatically via copper jaws and locking nuts followed by clamping in compressive direction via counterpieces (shims, setscrews and nuts) on both sides. The setup is illustrated in Fig. 7.

Specimen stress and strain were determined precisely throughout the thermo-mechanical tests. An air cooled Epsilon diametral extensometer (C-Gauge) was used to measure the specimen diameter in situ. Gleeble ${ }^{\circledR}$ 3800 physical forging simulations were performed stress controlled using the true stress signal from the extensometer. The relationship between diameter and true stress follows Eq. (1).

$$
\sigma=\frac{F}{A}=\frac{4 F}{\pi\left(d_{0}+\Delta d\right)^{2}} .
$$

where $\sigma$ is true stress, $\mathrm{F}$ is force, A stands for area, $\mathrm{d}_{0}$ is the initial diameter and $\Delta \mathrm{d}$ is the change in diameter.

Resulting thermal stresses $\left(\sigma_{\text {therm }}\right)$ due to thermal expansion and contraction during heating and cooling, respectively, were calculated according to Eq. (2) and verified in calibration tests.

$$
\sigma_{\text {therm }}=-E \alpha \Delta T .
$$




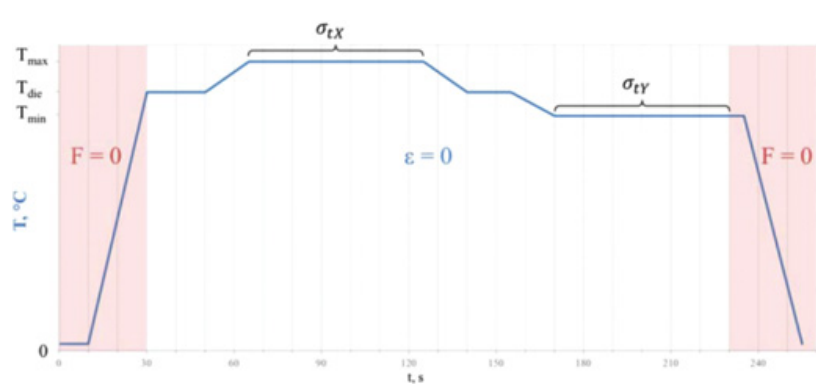

Figure 8. Temperature cycle used for calibration measurements.

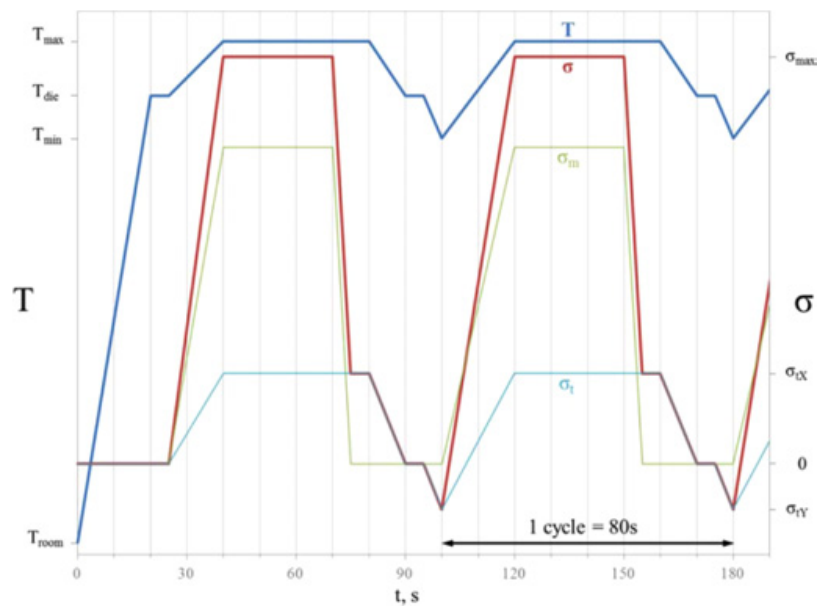

Figure 9. Thermal and mechanical load cycles used in physical forging simulations.

Table 2. Comparison of testing cycles up to a total plastic strain of 0.1 for each alloy and maximum mechanical stress level.

\begin{tabular}{lccc} 
& & Allvac $^{\circledR}$ & Haynes $^{\circledR}$ \\
Inconel $^{\circledR}$ & ${ }^{\circledR} \mathbf{7 1 8}$ & $\mathbf{7 1 8 P l u s}^{\text {TM }}$ & ${ }^{\circledR}$ \\
\hline$-\mathbf{4 5 0} \mathbf{M P a}$ & $1 \pm 0.5$ & $10 \pm 1$ & $80 \pm 30$ \\
$-\mathbf{3 5 0} \mathbf{~ M P a}$ & $10 \pm 3$ & $50 \pm 10$ & $480 \pm 80$ \\
$-\mathbf{3 0 0} \mathbf{M P a}$ & $40 \pm 10$ & $160 \pm 50$ & $1230 \pm 110$
\end{tabular}

$\sigma_{\text {therm }}$ is the stress resulting from a change in temperature, E stands for Young's Modulus and $\Delta \mathrm{T}$ is the temperature difference. Total stress $\left(\sigma_{\text {tot }}\right)$ applied to the test specimen is consequently the sum of mechanical stress $\left(\sigma_{\text {mech }}\right)$ and $\sigma_{\text {therm }}$ (see Eq. (3)),

$$
\sigma=\sigma_{\text {tot }}=\sigma_{\text {mech }}+\sigma_{\text {therm }} .
$$

A schematic diagram of the calibration tests is depicted in Fig. 8.

To simulate a real TiAl turbine blade forging process, the tests consisted of following sequences:

- heating up from room temperature to $\mathrm{T}_{\text {die }}\left(1^{\text {st }}\right.$ run)

- holding at $\mathrm{T}_{\text {die }}$

- heating up from $\mathrm{T}_{\text {die }}$ to $\mathrm{T}_{\max }-$ applying stress $\sigma_{\text {tot }}$

- holding at $\mathrm{T}_{\max }$
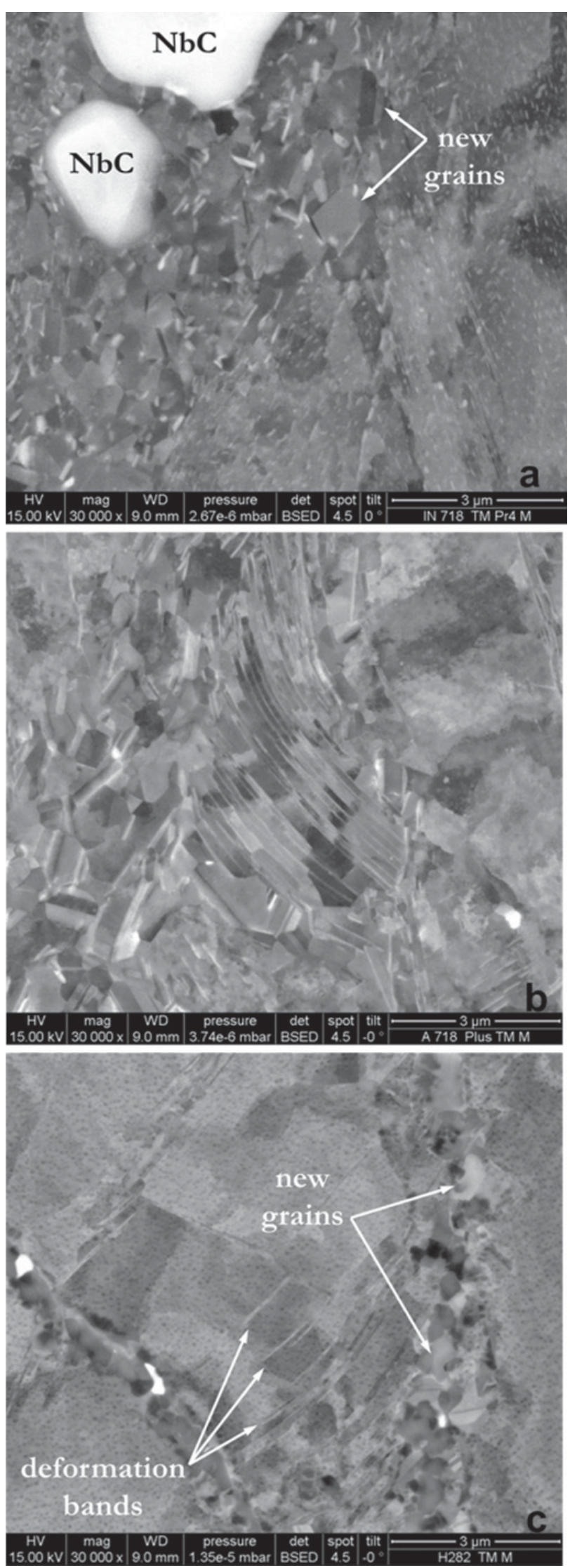

Figure 10. FEG-SEM images of deformed Inconel ${ }^{\circledR} 718$ (a), Allvac ${ }^{\circledR} 718$ Plus ${ }^{\mathrm{TM}}$ (b) and Haynes ${ }^{\circledR} 282^{\circledR}$ (c). 
Table 3. Minimum strain rate of the three alloys during physical forging simulation.

\begin{tabular}{cccc} 
& & Allvac $^{\circledR}$ & Haynes $^{\circledR}$ \\
& Inconel $^{\circledR} \mathbf{7 1 8}$ & 718Plus $^{\text {TM }}$ & $\mathbf{2 8 2}^{\circledR}$ \\
\hline$-\mathbf{4 5 0} \mathbf{M P a}$ & $(-2.0 \pm 0.6) \cdot 10^{-3}$ & $(-1.2 \pm 0.3) \cdot 10^{-4}$ & $(-1.3 \pm 0.4) \cdot 10^{-5}$ \\
$-\mathbf{3 5 0} \mathrm{MPa}$ & $(-1.2 \pm 0.1) \cdot 10^{-4}$ & $(-2.5 \pm 0.4) \cdot 10^{-5}$ & $(-1.1 \pm 0.5) \cdot 10^{-6}$ \\
$-\mathbf{3 0 0} \mathbf{M P a}$ & $(-3.2 \pm 0.7) \cdot 10^{-5}$ & $(-7.5 \pm 1.8) \cdot 10^{-6}$ & $(-5.2 \pm 1.0) \cdot 10^{-7}$
\end{tabular}

- removal of applied stress $\sigma_{\text {mech }}$

- cooling from $\mathrm{T}_{\max }$ to $\mathrm{T}_{\text {die }}-$ removal of $\sigma_{\text {therm }}$

- holding at $\mathrm{T}_{\text {die }}$

- cooling from $\mathrm{T}_{\text {die }}$ to $\mathrm{T}_{\min }$ - applying $\sigma_{\text {therm }}$

- holding of $\mathrm{T}_{\min }$

- heating up to $\mathrm{T}_{\mathrm{die}}-$ removal of $\sigma_{\text {therm }}$.

$\mathrm{T}_{\text {die }}$ is the die temperature during forging (above $700^{\circ} \mathrm{C}$ ), $\mathrm{T}_{\max }$ is the maximum temperature (about $90^{\circ} \mathrm{C}$ above $\mathrm{T}_{\text {die }}$ ) at the die surface during a forging cycle and $\mathrm{T}_{\text {min }}$ is the minimum surface temperature (about $70^{\circ} \mathrm{C}$ below $\mathrm{T}_{\text {die }}$ ) due to cleaning of the die with compressed air. A schematic overview of the temperature and stress sequence is illustrated in Fig. 9.

\section{Results and discussion}

Main performance criterion for die material was defined as service time (denoted by testing cycles) until a maximum plastic strain of 0.1 was reached.

Table 2 summarizes the resulting number of cycles for each alloy.

To better interpret results from physical simulations, deformed microstructures were investigated by use of light optical microscopy and field emission gun scanning electron microscopy. For each alloy, a non-linear strain after preceding linear behavior at low strains was observed, similar to the tertiary and secondary creep stages described in literature. In this non-linear strain dependency of time, the main softening mechanism was identified to be the formation of new grains via recrystallization (see Fig. 10). These new grains are more or less free of precipitates. Specifically, coarsening of $\gamma^{\prime \prime}$ phase and partial transformation to $\delta$ phase was observed for Inconel ${ }^{\circledR}$ 718. The $\gamma^{\prime}$ phase partly transformed to $\delta$ phase in Allvac ${ }^{\circledR} 718$ Plus $^{\text {TM }}$, which is in good correlation with [6]. Haynes ${ }^{\circledR} 282^{\circledR}$ showed no transformations, but slight coarsening of $\gamma^{\prime}$. From microstructural point of view, it can be concluded, that the outstanding performance of Haynes ${ }^{\circledR} 282^{\circledR}$ compared to the other two alloys is based on the stability and morphology of grain boundary carbides which delay recrystallization. Furthermore, the high amount of $\gamma^{\prime}$ phase and its high thermal stability favor the application of Haynes ${ }^{\circledR} 282^{\circledR}$ as die material.

To determine the dominating hot deformation mechanism, the stress exponent ( $\mathrm{n}$ ) for each alloy in the linear low strain region of the obtained strain curves was evaluated. A simplified creep approach was used neglecting varying temperature and stress during thermo-mechanical tests and assuming no microstructural changes during the early

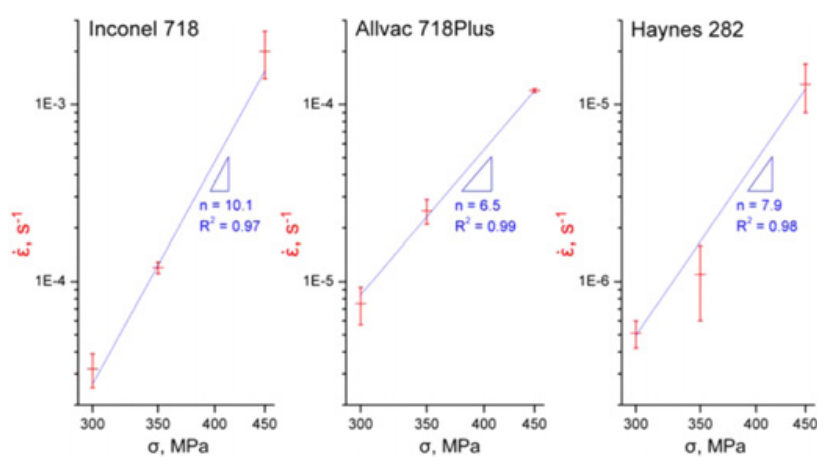

Figure 11. Stress dependence of minimum strain rates during physical forging simulations.

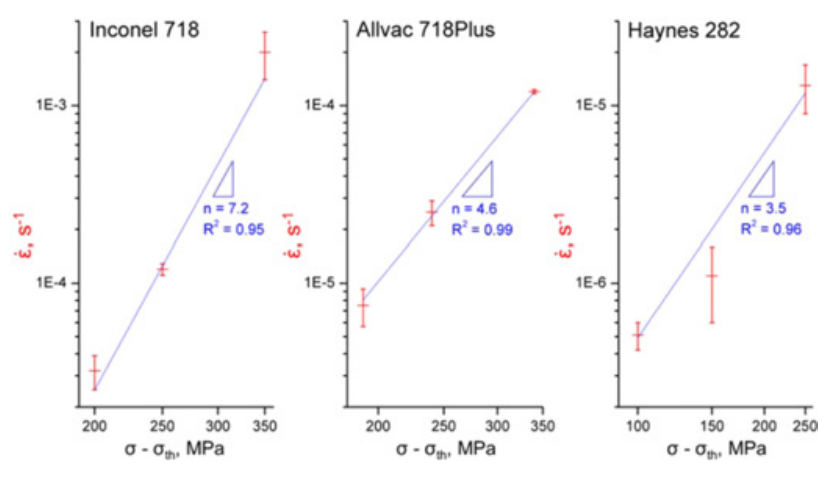

Figure 12. Stress dependence of minimum strain rates corrected by threshold stress.

stages of deformation (see Eq. (4)).

$$
\begin{array}{r}
\dot{\varepsilon}_{\text {min }}=\mathrm{K} \sigma^{n}, \\
\log \dot{\varepsilon}=\log K+n \log \sigma
\end{array}
$$

The minimum strain rate $\varepsilon_{\text {min }}$ for each alloy is shown in Table 3.

According to Eq. (4) the stress exponent can be found as inclination of a minimum strain rate vs. testing stress plot (see Fig. 11).

However, results of this simplified assumption do not correlate to real testing results. The approach was refined by adding threshold stress $\sigma_{\text {th }}$ into Eq. (4). This stress is needed to detach dislocations from precipitates and is often assumed to be proportional to the Orowan stress. Using material parameters at maximum testing temperature and maximum compression stress, $\sigma_{\text {th }}$ can be calculated by use of Eq. (5) [7].

$$
\sigma_{\text {th }}=0.06 M \tau_{0} \ln \sqrt{\frac{8}{3} \frac{d}{b}}
$$


where $\mathbf{M}$ is the Taylor factor, $\tau_{0}$ is Orowan stress, $\mathrm{d}$ the mean particle diameter and b the Burger's vector. Combining Eqs. (4) and (5) leads to Eq. (6)

$$
\dot{\varepsilon}_{\text {min }}=K\left(\sigma-\sigma_{t h}\right)^{n} .
$$

Threshold stresses $\sigma_{\text {th }}$ for Inconel $^{\circledR}$ 718, Allvac ${ }^{\circledR}$ 718Plus ${ }^{\mathrm{TM}}$ and Haynes ${ }^{\circledR} 282^{\circledR}$ were calculated to be $100 \mathrm{MPa}, 110 \mathrm{MPa}$ and $200 \mathrm{MPa}$, respectively.

Linear plots of minimum strain rates vs. testing stresses considering threshold stresses are depicted in Fig. 12.

Considering the correction by $\sigma_{\text {th }}$, the derived stress exponent values for Inconel ${ }^{\circledR} 718$, Allvac ${ }^{\circledR} 718$ Plus $^{\mathrm{TM}}$ and Haynes ${ }^{\circledR} 282^{\circledR}$ are $7.2,4.6$ and 3.5, respectively. While $\mathrm{n}$ values around 4 are typically related to deformation mechanism dislocation creep, the $\mathrm{n}$ value for Inconel $^{\circledR} 718$ is still too high after correction. An explanation could be the fact, that $\gamma^{\prime}$ phase was not observed experimentally and therefore neglected in threshold stress calculation.

\section{Conclusion}

Physical forging simulations on a Gleeble ${ }^{\circledR} 3800$ testing system were conducted to evaluate three different $\mathrm{Ni}$ base superalloys for application as die material in a hot-die forging process of TiAl turbine blades. Based on numerical simulation, temperature and compression stress profiles were defined. A maximum plastic strain of 0.1 was set as performance criterion. The number of testing cycles showed large differences in temperature stability of all three alloys. Subsequent microstructure analyses showed changes in precipitation distribution and morphology as well as recrystallization. The dominating deformation mechanism was identified as dislocation creep by determining stress exponents for all three alloys. From the results discussed above, it can be concluded that the better performance of Haynes ${ }^{\circledR} 282^{\circledR}$, under tested conditions and compared to the other two alloys, is based on the stability and distribution of grain boundary carbides which retard softening by recrystallization.

The present work was financially conducted within the framework of the CleanSky initiative of the European Commission in project DAFNE (Grant Agreement No 278084). Authors would like to thank USTEM (Vienna University of Technology) for the FEG-SEM facilities.

\section{References}

[1] D. Huber, M. Stockinger, H. Clemens, 2012 MRS Fall Meeting, 1516, 23, (2012)

[2] R.B. Bhavsar, A. Collins, S. Silverman, Superalloys 718, 625, 706, and Various Derivatives, 47, (2001)

[3] W.D. Cao, R.L. Kennedy, Recommendations for Heat treating Allvac ${ }^{\circledR} 718$ Plus ${ }^{\circledR}$ Alloy Parts, (2006)

[4] L.M. Pike, Superalloys 2008, 191, (2008)

[5] F. Duschel, Master Thesis, (2013)

[6] W.D. Cao, Superalloys 718, 625, 706, and Various Derivatives, 165, (2005)

[7] I. Holzer, PhD Thesis, (2010) 